\title{
The evolving landscape of climate services in sub-Saharan Africa: What roles have NGOs played?
}

\author{
Blane Harvey $^{1,2}$ (D) $\cdot$ Lindsey Jones ${ }^{2,3} \cdot$ Logan Cochrane $^{4,5} \cdot$ Roop Singh $^{6}$
}

Received: 12 April 2018 / Accepted: 15 March 2019/Published online: 3 April 2019

(C) The Author(s) 2019

\begin{abstract}
With recent growth in funding and research on "resilience building", interest in climate services has risen dramatically. Included in this trend is an increased emphasis on the use of climate and weather information for a range of purposes across multiple scales. Nongovernmental organisations (NGOs) and other non-state actors across Africa have responded accordingly, and are increasingly acting as brokers, and sometimes producers, of climate services as part of their activities. Drawing on research from Burkina Faso and Ethiopia as part of the Building Resilience and Adaptation to Climate Extremes and Disasters (BRACED) programme, this paper critically examines the evolving climate services landscape and raises questions about what the future holds for climate services in sub-Saharan Africa. We ask two questions: How have national climate services in these countries evolved since the early $2000 \mathrm{~s}$ when they first came to prominence? And how have NGO contributions to these services evolved over time? Our findings highlight a considerable evolution in the aims and capacities of climate service systems over this period. NGOs have contributed to this progress on multiple fronts, but we note that important opportunities for innovation remain. We also raise concerns about how the current financing and governance models may influence priority setting and the sustainability of "projectised" services. Accordingly, we call for a better understanding how power and politics shape the development and deployment of climate services. This paper provides insight on the evolving landscape of climate services, actors involved in its provision and implications for the future.
\end{abstract}

This article is part of a Special Issue on "Putting Climate Services in Contexts: Advancing Multi-disciplinary Understandings" edited by Sophie Webber.

Blane Harvey

Blane.Harvey@mcgill.ca

Extended author information available on the last page of the article 


\section{Introduction}

Climate services have long been seen as a means through which vulnerability to environmental shocks and stresses might be reduced and livelihoods strengthened (Hulme et al. 1992; Ingram et al. 2002). However, they did not become a core focus for bilateral funding and non-governmental organisation (NGO) activity in developing countries until the early- to mid-2000s (Béné et al. 2014). Climate services are now seen to offer benefits across a range of scales in Africa, from safeguarding investments into national infrastructure from long-term change to helping the continent's smallholder famers "protect property and human lives, access risk-management mechanisms like index-based insurance, and create long-term plans for a future that will be highly dependent on rainfall patterns, droughts, floods and other natural disasters" (UNDP 2016: 7). Greater attention to climate services has coincided with the increasing use of resilience as a framing concept and "mobilising metaphor" (Béné et al. 2016) that bridges near-term readiness and response to climate and disaster risk with longer-term development agendas. This has generated new types of funding opportunities and partnerships, including scaled up investment into climate services as a means of reducing vulnerability and building resilience - though major regional disparities in investment remain (Georgeson et al. 2017).

Despite these advances, there are continued calls for scaling up support for climate information systems and services (Hewitt et al. 2012; Tall et al. 2014). Amidst this changing landscape, some are raising concerns about the coherence of these many streams of activity (Jones et al. 2016). This paper takes a closer look at these evolutions drawing specifically on evidence from two countries, Burkina Faso and Ethiopia. It draws on recent experiences from four consortia using climate services as a tool for resilience building in the Building Resilience and Adaptation to Climate Extremes and Disasters (BRACED) programme. In so doing, we examine how national climate services have evolved within these two countries over the past 1520 years and NGO contributions to these evolutions. Improving our understanding of these dynamics may inform more strategic investment into state and non-state climate services development in sub-Saharan Africa and give us a clearer sense of the potential risks, opportunities and trade-offs of continued growth in this field. The findings may also suggest the need for a closer integration of perspectives from climate sciences with those of social and political sciences as well as with local knowledges if investments into more robust climate services are to result in lasting social impact.

The following section outlines the background and methodology adopted for this paper. We then provide a broader contextualisation of donor investment, NGO roles and the governance contexts, highlighting both unique national experiences and more general trends. Our analysis adds to an emergent body of literature, informed by the social sciences, on the ways that stakeholder roles complement, overlap and sometimes compete in contributing to climate service delivery (Tarhule and Lamb 2003; Roncoli et al. 2009; Vaughan and Dessai 2014; Lourenço et al. 2015; Guido et al. 2016; Jones et al. 2016). We suggest that while there is an emerging common vision about the need for, and orientation of, climate service provision, there are diverse pathways that states and other actors are taking to implement it. We expand on this to highlight a "missing middle" of two-way brokering, translation and validation where 
NGOs and other non-state actors can support innovation and experimentation, particularly in two-way forms of engagement with local actors and knowledge holders. Finally, we also raise concerns about the sustainability and scalability of current activity as well as the driving forces behind the pathways of implementation.

\section{Methods}

This research was undertaken in two stages. The first stage of the study consisted of a review of existing literature on the roles of NGOs in supporting climate services, with a specific focus on knowledge brokering functions in developing country contexts (Jones et al. 2016). The recommendations and findings of that first stage highlighted key research gaps, as well as alternative approaches to assessing climate services, namely a systems or value-chain perspective (Fig. 1). A value chain approach involves the mapping of roles and functions at (and between) a variety of points within the climate services system. This helps to observe the relationships between actors and processes that enable the flow of data and decision-relevant information and invites a systemic assessment of service provision, rather than taking a single point of focus (Giuliani et al. 2017). Viewing climate information services from this perspective has been promoted elsewhere (e.g. CARE 2016; GFCS 2016) and was viewed as a positive shift by NGO representatives at the African Ministerial Conference on Meteorology's (AMCOMET) 2017 Africa Hydromet Forum (Powell et al. 2017). Our model of the chain pays particular attention to brokering and intermediary roles, where non-state actors have often been important players and are able to provide feedback loops from actors further down the value chain to those working in earlier stages of the chain (Jones et al. 2016; Guido et al. 2016). This is illustrated

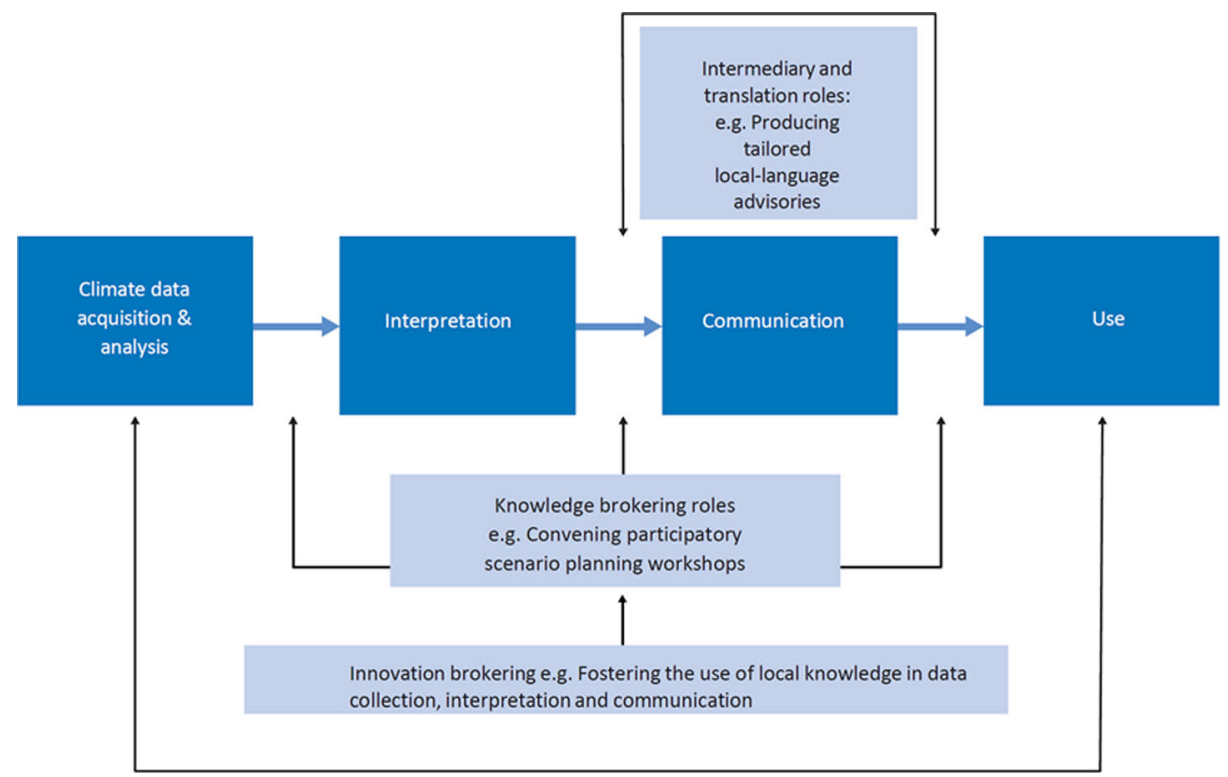

Fig. 1 Stylised value chain of common functions related to climate services (Jones et al. 2016) 
through the black arrows in Fig. 1. In line with past studies (Jones et al. 2016; Hammill et al. 2013), knowledge intermediary and translation roles are understood to make knowledge accessible and actionable, brokering roles enhance the understanding and use of knowledge in decision-making and foster co-production, while innovation brokering involves influencing the wider value chain to enable innovation in climate services.

Based upon the results of our desk review, two countries were selected for in-depth analysis. Burkina Faso and Ethiopia were chosen as countries that experience high levels of vulnerability to, and international investment in, climate change impacts (see Sect. 3.1 below). Both hosted BRACED-funded activities focused specifically on improving climate services and featured collaboration between the national meteorological services (NMSs) and NGOs in both instances. In addition, the two nations offer an opportunity for comparison due to the contrasting policy environments in which climate services operate (see Box 1; Harvey and Singh 2017; Cochrane and Singh 2017). While we focused our selection on countries where BRACED was undertaking programming, the study looked beyond BRACED activities at the wider national landscape of actions on climate change and resilience. Research questions were structured around two areas of inquiry, which guide the presentation of findings below: First, understanding the evolutions of national climate services and the drivers of that evolution, and second, critically examining the contributions of non-state actors (particularly development and humanitarian NGOs) to national climate services over time. The first question allowed us to establish the national context within which climate services are operating, and how this context has changed over time. The second forms the basis of our analysis within this study and our conclusions concerning the future of NGO contributions to climate services in sub-Saharan Africa.

The research questions sought to draw out the dynamic nature of actors and activities on climate services over the last two decades. To trace evolutions in the system over time, both country studies used available literature from approximately 2002-2003 as a baseline, tracing forward until early 2018. This choice was based upon the availability of similar studies for comparison (e.g. Tarhule and Lamb 2003) and because this was a period where both countries saw a rise in interest and investment into the potential use of climate services in development practice. While the focus of this study is specifically on climate services, we are also cognizant that broader changes over this period, such as the exponential growth in mobile phone use as well as wider information and communication technologies, have enabled new forms of engagement and exchange (Hammill et al. 2013). The evolutions we set out here must be viewed within this context.

We conducted 24 interviews in early 2017 through a combination of in-country field visits, interviews conducted virtually and interviews held at a major BRACED event in Entebbe, Uganda.

Key informants were identified via the literature review, actor mapping and snowball sampling from three categories of actors:

- Respondents directly engaged in data acquisition, analysis or interpretation for producing climate services $(n=7)$

- Representatives of humanitarian and development NGOs using climate information as part of resilience-building projects or programmes $(n=13)$ 
- Representatives from bilateral and international agencies that fund climate services or resilience-building programmes in the two countries $(n=4)$

Country visits also included participation in a 2-day workshop in each country, which focused specifically on the role of climate information in resilience-building, hosted by BRACED partners. The workshops included approximately 50 participants in each country. The data collected through desk-based research, interviews and workshop participation were used to produce two country studies using a common analytical structure that is reflected in the structure of this article (Harvey and Singh 2017; Cochrane and Singh 2017). The authors then conducted a thematic analysis across both cases to identify common trends and areas of contrast seen to be of significance. Finally, the themes identified were presented to a reference group of seven experts working on resilience and climate services at a pan-African scale to validate the findings and for input on their significance and generalizability to other African contexts. These included representatives from academia, international NGOs, NMSs and intergovernmental agencies.

Our analysis documents national trends in climate services. This is not always easy given the tendency for work on the delivery of climate services to be undertaken as pilots at sub-national scales and the degree of regional and international interaction around the acquisition and analysis of data in the production of forecasts. We focus on actors and initiatives that have country-wide uptake or influence, as well as more local initiatives that were being carried out by different actors in many parts of the country.

\section{Context}

\subsection{National development and the roles of non-state actors}

Like many other countries in sub-Saharan Africa, Burkina Faso and Ethiopia are characterised by a high dependency on agriculture (predominantly smallholder and rainfed) for revenues and employment. Over $80 \%$ of the population in both countries is employed in the agriculture sector. ${ }^{1}$ Consequently, both countries have extreme levels of vulnerability to the rising risk of climate-related shocks and stresses, respectively ranked as 163rd (Ethiopia) and 164th (Burkina Faso) on the ND-GAIN composite index of climate vulnerability and readiness in 2018 (gain.nd.edu). The growing threat of climate and disaster risk to national development trajectories has driven the creation of a suite of national strategies to address these risks as well as investment from bilateral and multilateral development agencies into large-scale programmes like BRACED (see Box 1). Calculations vary considerably but, by some estimates of climate-related official development assistance, exceeded US 400 million from 2010 to 2013 in Burkina Faso (Crawford et al. 2016), while Ethiopia received an average of US 101 million annually over this same period (Echeverria and Terton 2016). The initiatives funded through these investments have increasingly framed or identified themselves as "resilience building" and included investments into climate services as a component of their activities. For instance, Crawford et al.'s (2016) inventory of recent projects on vulnerability and climate impacts

\footnotetext{
${ }^{1}$ See yieldgap.org
} 
in Burkina Faso lists seven large programmes with a specific focus on the use of climate information. Of these seven, six specifically identify resilience building as a core objective, while the seventh has "resilience" in the name of the initiative.

\footnotetext{
The Building Resilience and Adaptation to Climate Extremes and Disasters (BRACED) programme was a 3 -year, $£ 110$ million programme funded by the UK Department of International Development. From 2015 to 2017, BRACED provided grants to 15 NGO-led consortia in Asia and sub-Saharan Africa, designed to provide large-scale investment into building resilience of vulnerable populations. Climate services featured in a range of different projects, with consortia investing in improved climate information acquisition and interpretation, communicating climate information to end users and engaging the private sector as alternative avenues for communicating climate information (BRACED 2017). The expected contribution of strengthening climate services in BRACED programming was in "improving [community] capacities to take appropriate action in light of expected trends and uncertainties will help equip communities to deal with climate changes." (Wilkinson et al. 2015: 4). While seasonal forecasts, communicated via radio, SMS and community forums, were the most prevalent type of information shared in Burkina Faso and Ethiopia, BRACED consortia also provided information on recurrent weather events such as monsoons (in Myanmar), and El Nino (in Kenya and Uganda), and on longer-term projections as part of national development planning processes (Silva Villanueva et al. 2016).
}

Four BRACED consortia were involved in this study - all of which sought to develop and or use climate services in their programming. These were:

In Burkina Faso:

- Zaman Lebidi: Strengthening resilience to adapt to the effects of climate change, led by Christian Aid

- Changing farming practices to prepare for heavy rain and high temperatures, led by Welt Hunger Hilfe In Ethiopia:

- Market approaches to resilience, led by Farm Africa

- CIARE: Supporting communities in Ethiopia to overcome the negative impact of climate change, led by Christian Aid

The consortia featured a combination of international and local NGO partners, specialist agencies on media (e.g. BBC Media Action; Internews), meteorology (e.g. the UK Met Office and national meteorological services from both countries) and, in some cases, academic research institutions (e.g. King's College London).

\section{Box 1 BRACED and its activities in Burkina Faso and Ethiopia}

NGOs and civil society organisations have historically had a strong role in delivering development and humanitarian activities at the local level in sub-Saharan Africa and are often seen as "last mile" service providers in a range of fields, from agriculture, to health and disaster response. This has often been financed through bilateral and multilateral aid, with NGOs filling gaps left by under-resourced state programming. This service delivery role has come with varying levels of oversight, regulation and coverage based on country context. Largely starting in the early 2000s, NGOs began to engage with climate services as a means to strengthen their service delivery activities in fields such as agricultural extension and disaster preparedness. In Ethiopia, this timing coincides with the deployment of early warning systems, the development of a large-scale social safety net and a shift towards poverty alleviation (and away from costly emergency response). In Burkina Faso, it coincides with the first instances of publicly disseminated seasonal forecasts - which had previously been seen as "experimental" (Ingram et al. 2002). Until this point, communities had largely relied on long-standing indigenous knowledge systems and traditional methods of forecasting (based on observations of flora, fauna, environmental conditions, and more) to inform their decision-making (Ziervogel and Opere 2010; Kalanda-Joshua et al. 2011; Niang et al. 2014). While highly 
respected and frequently effective at local scales, the value of these methods has been increasingly challenged by social factors including the erosion of local knowledge, and the accelerating pace of environmental change, which has affected the reliability of many indicators (Ziervogel and Opere 2010; Plotz et al. 2017). NGO and government efforts to promote "Western" forms of climate science and forecasting have frequently failed to meaningfully account for or engage with this existing knowledge base and its associated practices - a factor that is seen to partly explain the limited adoption of early climate service initiatives (Nyong et al. 2007; Ziervogel and Opere 2010; Crawley et al. 2018).

In addition to the traditional development and humanitarian NGOs, recent years have seen an increased presence of non-state organisations playing technical advisory roles on climate services, which contribute to analysis, capacity building and related research activities. These include research-intensive centres of expertise, as well as private sector enterprises in a number of countries. In Burkina Faso, for example, a private agrometeorological information provider has begun disseminating climate information via SMS within the BRACED programme (Visman et al. 2017). The extent to which this signals a major trend within the climate services landscape remains unclear, and the emergence of such actors is not consistent across countries. In Ethiopia, for instance, government policies have not facilitated a strong private sector engagement in the climate service environment.

\subsection{Evolutions in national meteorological services}

Emergence of a common vision Looking more specifically at the evolving role of national meteorological services (NMSs), our review of recent literature and interviews with key informants point to a common vision on climate services emerging among African countries and collaborating international partners. This vision affirms the importance of climate services to national development, the central role of NMSs as providers and coordinators of service delivery and the need for services to be "user-driven" (AMCOMET 2017; Lúcio and Grasso 2016). The Global Framework for Climate Services (GFCS), currently working with 18 countries across Africa to develop national frameworks, has proven influential in this regard, providing significant inputs to planning and capacity building of national actors. The way in which this vision is being pursued in each country proves to be highly dependent on structures of governance, national capacities and funder investments. For example, in Ethiopia, the National Meteorological Agency (NMA) plays a strong role in coordinating and directing climate services with a dedicated focal point within the agency (Cochrane and Singh 2017). In Burkina Faso, where the Agence Nationale de la Météorologie (ANAM) has historically struggled with limited capacity, a low profile and mixed mandates, it has had limited success in taking a coordinating role (Harvey and Singh 2017; Bain and Henley 2014).

Growing capacity but persistent gaps The view of climate services as a system that cascades information tailored through various actors until it reaches "users", who in turn provide feedback that is iteratively integrated into the system, remains a vision that has yet to fully materialise (Powell et al. 2017). While we have witnessed significant evolutions in the visions and technical capacities of NMSs since about 2002, some long-standing gaps persist. In terms of technical capacity, both countries boast greatly expanded observation systems featuring higher levels of automation (GFCS 2016; Cochrane and Singh 2017). In Burkina Faso, Diasso (2016) reports that their hydro-meteorological monitoring system "is set to become one of the most substantial in West Africa", while Ethiopia's NMA already manages 
more than 1300 data collection stations and is rapidly expanding its network of automatic weather stations (Cochrane and Singh 2017). These progressions reflect an enduring preference for infrastructure-led development from NMSs in sub-Saharan Africa which strengthen the technical capacities of the services but do little to engage build stronger links to users or to other knowledge systems. Recent studies and interview responses from NMAs continue to highlight infrastructure and capacity gaps in both countries; however, the progress made to date is significant.

In contrast, despite dramatic technological advances over this period, communication and user-engagement practices have seen much less evolution. NMSs in both countries produce a suite of products ranging from daily weather summaries to seasonal and decadal agrometeorological forecasts. Products are delivered in PDF format through email mailing lists and websites, or are presented directly to government agencies, but generally lack a systematic delivery system that reaches most citizens. As noted in a review of Burkina Faso's climate services, "there is a strong desire by the staff [of l'Agence Nationale de la Météorologie] to do more dissemination of information, but there is currently not the mandate nor the financial means to do everything they would like to do" (Bain and Henley 2014: 15). Where user-level services do exist, the feedback loop from local users back to information producers is largely absent or ineffective according to key informants. As such, there is still little evidence of the co-production of climate information between NMSs and users (including local knowledge holders) that is seen to be a key to producing useful and "useable" knowledge (Dilling and Lemos 2011; Meadow et al. 2015). The science-driven nature of national agenda setting is not unique to sub-Saharan Africa, having been documented across a range of contexts (e.g. Golding et al. 2017; Lourenço et al. 2015), but it poses challenges to the vision of the user-centred approach described above.

In both Burkina Faso and Ethiopia, respondents inside and outside of NMSs related an unease with communicating to non-expert audiences. This discomfort is attributed to concerns around mandate and capacity in some instances, as well as to the perceived risks of issuing inaccurate forecasts or alerts, and the political sensitivities associated with issuing seasonal forecasts predicting unfavourable agricultural conditions or reduced yields. This risk aversion is exemplified by a well-documented bias towards over-predicting "normal" seasonal rainfall by the Ethiopian NMA and the Greater Horn of Africa Climate Outlook Forum, likely driven by the wish to avoid the forecast being interpreted as an error (Korecha and Sorteberg 2013; Mason and Chidzambwa 2008). Meanwhile, in Burkina Faso, two respondents reported rumours of unfavourable seasonal forecasts being revised in dialogue with agricultural authorities to avoid having farmers opt out of planting for the coming season. The political nature of seemingly technical exercises such as seasonal forecasting has been highlighted elsewhere in recent literature on climate change adaptation (e.g. Eriksen et al. 2015; Naess et al. 2015). The above trends underscore continued challenges with the perceived relevance and trustworthiness of information, challenges that - in many ways - extend beyond issues of technical or institutional capacity.

Continued financial precarity Financial and human resource capacity constraints within NMSs have persisted over the period of our analysis and continue to affect the ability of national agencies in both countries to deliver on core aspects of their mandates, from maintaining observational infrastructure to recruiting and retaining staff and engaging 
with end users (UNDP 2016; Bain and Henley 2014). This has had a significant bearing on the pace of change in national systems and has prompted many NMAs to look for alternative sources of funding through a range of avenues, including public-private partnerships, charging for data and selling of services (particularly to the private sector) (UNDP 2016). As one NGO project director in Burkina Faso reported: "There is now a difficult dynamic between government agents, NGOs and donors-everything has a price. Accessing relevant information costs a huge amount and this has an effect on the sustainability of initiatives" (Interview, Feb 23, 2017). As a result, some organisations bypass the national services and get information from international sources that are free and easier to obtain. Another significant new source of funding in the case of both countries has been the rise of NMA involvement in externally funded projects with NGOs, bilateral or multilateral agencies and other non-state actors (explored below). The extent to which any of these will provide a sustained and significant source of financing remains uncertain and is heavily dictated by national governance contexts. In Burkina Faso, respondents noted that the recent transition of the NMS from a government department to an Agency provides it more autonomy to pursue public-private partnerships, whereas in Ethiopia, the NMS has been less receptive to private sector involvement or partnership. Recent scholarship has emphasised, however, that private sector engagement is no panacea (Pauw 2014; Webber and Donner 2017).

\section{Analysis: evolving roles of NGOs and non-state actors}

Having outlined the dynamic nature of climate service provision in Burkina Faso and Ethiopia, we now consider the contributions of non-state actors in both countries. The qualitative data collected in both countries point to significant evolutions in some aspects of the climate services landscape - as well as challenges that have persisted despite the rise in investment and activity in this field.

\subsection{Evolutions in NGO contributions to climate services}

In examining evolutions in the delivery of climate services in Burkina Faso and Ethiopia, and the roles of NGOs in this delivery more specifically, experts, practitioners and government personnel point to significant evolutions in capacities and practice since the baseline period of 2002/2003. NGOs and other non-state actors have had a growing presence in the climate services landscape, bringing in new capacities and innovations in practice. Once primarily used as partners for facilitating access to communities and remote field sites, NGOs have emerged as playing a far wider set of roles - including data collection, technical analysis and translation of forecasts into more usable formats and products. This has largely been undertaken through relatively short-term, externally funded projects and pilots implemented in select sets of communities or districts. In some instances, such as the use of "roving seminars" developed through the Climate Forecasting and Agricultural Resources (CFAR) project in Burkina Faso (Roncoli et al. 2009), piloted innovations have been taken up into the practices of NMSs, but in a far greater number of cases, the pilots have been implemented and reported upon independent from formal government practice. This commonly occurs through parallel accountability structures of international funding agencies and bilateral donors-leading to frequent complaints of a lack of coherence. 
Much as they were 20 years ago, NGOs continue to serve as last mile links for translating, communicating and supporting the use of information and knowledge to rural communities in sub-Saharan Africa (Tarhule and Lamb 2003). Looking at the value chain of climate services (Fig. 1), the literature and qualitative data highlight a predominance of activities led by nonstate actors focused between the communication and use of climate information-often innovating by integrating the use of new and/or appropriate technologies. In the context of the BRACED projects, for instance, this has included the use of tailored communication approaches such as mobile phone messages, drama and song, local language radio broadcasts and radio listening groups targeting rural households and traditional networks with weather and climate information (Silva Villanueva et al. 2016; Harvey and Singh 2017; Cochrane and Singh 2017). Many of the practices cited here are not new, having been used by organisations such as Farm Radio International for years. We do find innovation in terms of the application of these approaches in new settings and with new stakeholders (see Grist and Harvey 2017) and note their clear departure from the usual practices of NMAs in the countries. Across nearly all of these examples, delivery of the services has been initiated and sustained by the NGO partners through project-based funding.

Looking at the opposite end of the value chain, we find significant changes in the contributions of non-state actors in the acquisition and analysis of climate informationgoing well beyond the use of community rain gauges by NGOs, as practiced across subSaharan Africa for decades (Dinku et al. 2014b). Regional centres of excellence on climate information and climate services have become prominent contributors of data, analysis and capacity in both Burkina Faso and Ethiopia, as well as the wider Sahel and Horn of Africa regions. The German-sponsored West African Science Service Center on Climate Change and Adapted Land Use (WASCAL) and the CGIAR's Climate Change Agriculture and Food Security (CCAFS) consortium were two widely cited examples. In other cases, development and humanitarian NGOs including Welthungerhilfe and Action Contre la Faim have undertaken data collection and analysis, particularly around rainfall and vegetation dynamics, to inform their in-country work. This is indicative of the shifts in regional expertise.

In contrast, however, we find uneven development in the integration of local and indigenous knowledges into the production, use and dissemination of climate information- despite its frequent discussion within the literature and significance for effective knowledge brokering (Niang et al. 2014). While some initiatives have sought to tap into endogenous networks for the dissemination of forecasts, we find less evidence of the regular involvement of local or indigenous knowledge in the production, interpretation or contextualising of information to ensure its relevance to local contexts. Evidence of a willingness to engage in consensus or integration-based forecasting between Western and indigenous knowledge systems is also rare. Widely cited exceptions here are the engagement of indigenous and local communities in the Climate Outlook Forums in the Horn of Africa (Harrison et al. 2007) and the participatory forecasting undertaken through the CFAR project (Ingram et al. 2002). In Ethiopia, there are some pilot examples of using traditional information sharing modalities to broaden the reach of climate information, such as having radio listening groups in pastoralist areas. However, this remains largely a process whereby climate services are transmitted via indigenous knowledgesharing processes or their communication modalities. Cases of intentional knowledge coproduction between Western and local or indigenous knowledge climate forecasts (e.g. Guthiga and Newsham 2011) remain scarce. This may point to more fundamental challenges in reconciling the processes and epistemic foundations of indigenous forecasting with the current scientific approaches that dominate NMS practices (Krauss and von Storch 2012). 


\subsection{System-level impacts, implications and limitations of a scaled up role}

Growing investment by bilateral and multilateral funders via programmes led by non-state actors has yielded benefits for under-resourced NMSs (Dinku et al. 2014a). Through collaboration in an ever-growing number of initiatives led by NGOs, universities and other climate, humanitarian, and development agencies, NMSs have secured investments into monitoring infrastructure, training and education opportunities for staff and funding to cover salaries and expenses for field-based personnel. These investments have often been the product of negotiation aimed at addressing both project needs and wider NMS priorities (for instance, providing tailored information contingent upon the purchase of additional monitoring stations).

Similar types of government and non-state actor collaborations on climate services have existed since the late 1990s, for instance, as part of the US-funded CFAR project (Roncoli et al. 2009), but they have grown in number and scale as investment into climate resilience has risen. Collaborations and project-based funding have filled gaps left by decades of under-investment into national climate services and provided opportunities for more novel approaches to user engagement than might otherwise have been pursued, at least in the short term. The growing prominence of these collaborations, and rising NGO capacity to initiate and contribute to them, sits in contrast with earlier views that "most NGOs are ill-equipped in terms of personnel and expertise" to expand their contributions in the area of climate and environmental information (Tarhule and Lamb 2003: 1749).

Despite the concrete benefits offered to national services, however, the rise of investment and partnerships has also raised concerns-namely around alignment, coordination and coverage of investments and services within the value chain. First, activities funded through bilateral and multilateral agencies may speak to national priorities but are rarely fully aligned with them-instead reflecting a combination of funder preferences, implementing agency interests and contextual considerations alongside these priorities (Jones et al. 2018). This can result in resources being allocated to areas that are not aligned with national priorities or create gaps in areas of investment that are less appealing to funders, such as infrastructure maintenance costs. In the words of one expert with experience working across multiple countries:

NGOs are all going to different donors and doing their own thing. They are filling the gaps operationally but not necessarily building into the [climate services] system. The pilots they lead are well-resourced and often successful but really hard to scale up. There's a real risk of creating parallel systems, and the lack of feedback mechanisms and disconnections mean that the overall coherence of the system is lacking. (Interview, Feb. 1, 2017)

The individual interviews, workshops and focus group discussions conducted for this study also highlighted similar challenges of alignment and coordination between the priorities being set through regional and intergovernmental processes on climate services such as the GFCS.

For some experts and practitioners in Burkina Faso and Ethiopia, these coordination challenges present not only questions of efficiency and sustainability of services but also concerns for their trustworthiness. Ethiopian respondents observed that NGOs have often taken on communication functions related to forecasts without also assuming interpretation and quality assurance roles, and the lack of coordination within the value chain may lead to NGOs transmitting information with the assumption that it has been validated elsewhere, 
potentially resulting in a further spread of unreliable or partial information. Addressing this risk may actually present new opportunities for NGOs, as we explore in Sect. 5. Government response to these coordination challenges is highly context dependent. For example, Ethiopia has sought to address these risks by appointing a coordinator based within the NMS and closely vetting all proposed initiatives, while no similar move has occurred in from within the NMS in Burkina Faso.

Beyond the concerns of alignment of investments and coordination of activities, there are also concerns regarding the robustness of service coverage under a "projectised" model of funding (Jad 2007) that is characterised by time-bound activities operating in a limited geographic area. The reasons for this concern are twofold. On one hand, NGO-led services such as those described above face continuous challenges in sustaining activities beyond project cycles. This means there is no assurance of their being sustained even after considerable effort is often made to build community engagement with the services. At the same time, NMS staff in both countries already describe their capacity to deliver core services as overstretched. This is exacerbated by the additional demands of delivering and reporting on multiple projects concurrently. There are concerns that a continued rise in project activities will affect NMS performance on both core and project activities and questions about what will be prioritised.

Combined, these points raise questions (highlighted by multiple respondents) about the suitability of project-based funding secured through NGO-NMS collaborations as a core component of NMS funding models for delivering services. Meanwhile, alternative funding models such as recent proposals to use public-private partnerships (PPPs) (UNDP 2016) to leverage investment have been met with scepticism (in Burkina Faso) or dismissal (in Ethiopia). There are also fears that charging for data (a current alternative in both countries) may create tensions with international funding partners. This signals an important challenge amid calls to stimulate increased demand for reliable and robust climate services across the continent.

\section{Conclusions}

Recent decades have seen systems for climate service delivery take significant positive steps forward across much of Africa. No longer are unidirectional models of communication accepted as the norm; many NMSs are espousing user-centred service design and are embracing the inputs and contributions of wider non-state actors (Dinku et al. 2014a). It is here where this paper adds to an emergent literature on climate service delivery, focusing in particular on the role of NGOs and other non-state actors that are at the heart of this recent transition. As the case studies from Burkina Faso and Ethiopia highlight, NGOs are offering novel ideas for communication, brokering and knowledge sharing. They also bring a new range of skills and capacities as well as disruptive innovations into national delivery systems. More importantly, climate services have transitioned from being an issue of low political priority with few funding opportunities in Africa to one supported by a growing range of funders as it rapidly rises up the development agenda (buoyed in large part by financial and political momentum behind the focus on resilience) (Jones et al. 2016). While these gains are significant, our study highlights four particular trends that must be addressed if climate service systems in many sub-Saharan African countries are to be efficient, robust and sustainable. 


\subsection{Leveraging the full potential of non-state actors}

While the role of NGOs as knowledge brokers and intermediaries has been widely called for (Tall et al. 2014; Guido et al. 2016), much of the NGO work has so far focused on last mile communication and outreach with end users. While we see rising data collection and analysis capacities among some NGOs and non-state actors, our research points to a "missing middle" of activities in the value chain where they could play important roles in two-way brokering, interpretation and translation of climate information. For example, not only are NGOs positioned to communicate the complexities of climate information to non-technical audiences, they serve an equally important role in listening and ensuring that the needs and insights of end users are recognised and communicated back to national-level producers of climate information (Vaughan and Dessai 2014).

Specific roles that are particularly suited to NGO strengths in support of climate service delivery include the following: knowledge brokering, enhancing understanding and use of knowledge in decision-making and fostering co-production; innovation brokerage, encouraging innovation in how climate information is produced and used; knowledge translation, promoting two-way flow of information and knowledge between producers and users of climate information; and information intermediaries, ensuring that information is communicated and available to wider audiences (Jones et al. 2016). In many ways, this echoes and extends wider calls for NGOs and other civil society organisations to play stronger roles as boundary agents at science-policy interfaces of other environmental challenges (Huitema and Turnhout 2009) - leveraging the unique set of skills, networks and authority afforded to them in mediating between producers and users of climate information.

These processes should be used to improve the relevance of climate services and products as well as giving formal providers new insights into local climate dynamics, informed by local and indigenous knowledge. The role of NGOs as brokers of a bottom-up exchange of knowledge is all too often under-appreciated and should be given greater support and acknowledgement (Windrum et al. 2016). This is an especially crucial dimension given the implications of long-standing divides between Western and indigenous forecasting approaches, communication networks and knowledge systems on the perceived relevance and use of NMS forecasts at local scales (Krauss and von Storch 2012).

While NGOs bring capacity for innovation and alternative funding streams to the value chain, it is also important to note the inherent risks of "blind enthusiasm": NGOs jumping in to perform new roles without the skills needed to perform them. Experiences from both Burkina Faso and Ethiopia, as well as across the wider BRACED network, suggest that more can and should be done to provide capacity support to NGOs that are assuming new roles in the production and interpretation of climate information (Silva Villanueva et al. 2016).

\subsection{What happens when the well runs dry?}

The interest of funding agencies to support climate services is undoubtedly positive, but it comes with a number of well-documented drawbacks. As noted in Sect. 4.2 above, climate service activities increasingly suffer the effects of "projectisation", including funding modalities that operate on short (2-5 year) timescales, a focus on predefined output and results and a drive towards demonstrating immediate impacts (Jones et al. 2015). While some of these traits may be conducive to piloting new approaches or short-term interventions in the climate service value chain, they may not be conducive to shifting norms of practice. Also important to 
consider is what happens when climate services and resilience inevitably fall down the development agenda and investments like those funding BRACED decline. ${ }^{2}$ African climate services are right to be capitalising on the recent political interest in the sector but must guard against the "boom and bust" nature of funding trends that have been witnessed in the past, for instance with the microfinance sector (Bateman and Chang 2012).

Bolstering observational networks and infrastructure, enhancing the technical capacity of NMSs and fostering new and meaningful partnerships between different stakeholders take considerable time and resourcing (Vaughan and Dessai 2014). The current lack of promising alternatives for sustained funding underscores a real risk in terms of consolidating and sustaining the gains of recent investments. While there is clearly no single way forward, decisions as to the role and prominence of new alternatives - be they private sector or other - should be taken in the context of existing political, economic and ethical priorities in each given country.

\subsection{Finance-driven agenda setting}

Evolutions in the climate service systems of both Burkina Faso and Ethiopia have been driven by a range of actors, each responsible for setting (somewhat) different agenda priorities. On one side, multilateral efforts such as the GFCS are keen to ensure that national priorities form the basis of climate service investments across Africa, built around a shared set of principles for climate services (Lúcio and Grasso 2016). However, while countries express enthusiasm about the GFCS process, their own investment prioritisation does not always align with these principles, frequently prioritising of investment into infrastructure and data analysis over other areas (Harvey and Singh 2017). Meanwhile, bilateral and multilateral funders from the humanitarian and development spheres are receptive to a country-driven approach, but their domestic political agendas and aid priorities tend to shape investment flows (Jones et al. 2015), meaning that national strategies risk being bypassed. The arrival of significant new investors like the private sector could bring further uncertainty to priority setting (Webber 2017).

The extent to which funding trends re-shape national strategies is largely dependent on structures of governance and governments' relationship with investing partners such as bilateral donors. For example, while Burkina Faso has a new national strategy supported through the GFCS, many of the climate service activities being implemented are via support from global and regional programmes (such as BRACED) and are largely operating in parallel to this strategy. In contrast, Ethiopia sees its own government, and the vision that it sets out, as the primary vehicle for climate service delivery, and investments must fall within the remit of the existing national frameworks. Addressing these disparities requires a shift in how programmes aimed at supporting climate services are designed, implemented and evaluated. In particular, emphasis should be placed on extensive in-country consultative engagements prior to the launch of programmes to ensure that they align effectively with national needs and existing frameworks. Regional and multilateral processes or bodies like AMCOMET and GFCS have, in our view, continued roles to play in supporting the development of evidence-informed national priority frameworks and of working with the international community to build broad-based support for them.

\footnotetext{
${ }^{2}$ This is perhaps most clearly illustrated by the case of BRACED itself, which was intended to be implemented in two phases over up to 10 years, but is now being wound down at the end of its first phase (Malo 2019).
} 


\subsection{Engaging with the politics of climate services}

Evidence from across the climate services value chain from investment decisions to user engagement (or lack thereof), highlight the political dimensions of these services and the value judgements and trade-offs being made. Choosing to guide climate investments solely through strategies led by national governments and NMSs provides them with greater legitimacy but relinquishes decision-making control. Opting to bypass national structures sends an opposing, yet equally strong message. Some decisions, such as consensus setting around regional seasonal forecasts or the prioritisation of particular sectors or user groups in services, continue to be viewed by many as largely technical and value neutral. The same can be said of decisions to prioritise further development of technical and observational capacities rather than engaging with other knowledge holders or knowledge types to produce, validate or communicate forecasts. While this message is certainly far from new (see Vaughan and Dessai 2014), many of the trends identified through this study suggest that the call to recognise the political dimensions of climate services is not being heeded.

To address this gap, researchers and funders of climate services must place greater emphasis on understanding the political and economic implications of climate service investments. This seems particularly pressing in a context where many governments in sub-Saharan are currently debating pathways to more sustainable models for financing national climate services and seeking to encourage more widespread use of the services. Understanding how politics and interests shape climate services will require the use of analytical tools such as political economy analysis (PEA) - approaches that currently play a limited role in decision-making processes in this field - as well as investments in more meaningful and inclusive consultative processes for planning and designing future work on climate services. It should be noted here that political and institutional barriers to the uptake of climate information are by no means limited to a sub-Saharan Africa context. Indeed, Bruno Soares and Dessai (2016) describe how, in Europe where climate services are comparatively well-resourced and accessible, the majority of organisations across eight key sectors fail to use seasonal climate forecasts in their decision-making processes. Tools such as PEA are now being used by European researchers to identify barriers and enablers to effective climate service delivery and better coordination or roles and activities across relevant stakeholders (Reinecke 2015; Bruno Soares et al. 2018).

In re-tracing the rapid transformation of the climate services landscape in Burkina Faso and Ethiopia, this study has highlighted the important roles that have been assumed by NGOs and other non-state actors and how they continue to drive innovations in both financing and the delivery of information in the sector. With this said, the study has also identified challenges related to the coherence, agenda setting and financing that raise questions about future evolutions in the sector. The more systemic analytical lens afforded by a value chain approach reveals the extent to which these challenges are collective - involving national governments, international funders and governance bodies and non-state actors that include NGOs and the private sector, in longer-term solutions. While our analysis speaks to the experiences of two countries, we feel they are of relevance to a great many other contexts in sub-Saharan Africa, and hope that they will stimulate further dialogue and analysis, and ultimately may inform more strategic investment into state and non-state climate services development in sub-Saharan Africa.

Acknowledgements The authors wish to thank BRACED partners in Burkina Faso and Ethiopia for their contributions and feedback on earlier versions of this paper. 
Open Access This article is distributed under the terms of the Creative Commons Attribution 4.0 International License (http://creativecommons.org/licenses/by/4.0/), which permits unrestricted use, distribution, and reproduction in any medium, provided you give appropriate credit to the original author(s) and the source, provide a link to the Creative Commons license, and indicate if changes were made.

\section{References}

AMCOMET (2017) Africa Hydromet Forum Communique. Addis Ababa, Ethiopia. https://www.gfdrr. org/sites/default/files/documents/AMCOMET\%20Africa\%20Hydromet\%20Forum\%20Communique\%20\%2023\%20Sept.pdf. Accessed 25 Mar 2019

Bain C, Henley E (2014) Baseline review of Météo Burkina for BRACED programme. UK Met Office. Exeter: United Kingdom

Bateman M, Chang H-J (2012) Microfinance and the illusion of development: from hubris to Nemesis in thirty years. World Econ Rev 1 https://ssrn.com/abstract=2385482

Béné C, Newsham A, Davies M, Ulrichs M, Godfrey-Wood R (2014) Resilience, poverty and development. J Int Dev 26:598-623

Béné C, Headey D, Haddad L, Von Grebmer K (2016) Is resilience a useful concept in the context of food security and nutrition programmes? Some conceptual and practical considerations. Food Secur 8(1):123-138

BRACED (2017) BRACED resilience exchange: what have we learned so far? www.braced-rx.org. Accessed 25 Mar 2019

Bruno Soares M, Dessai S (2016) Barriers and enablers to the use of seasonal climate forecasts amongst organisations in Europe. Clim Chang 137(1-2):89-103

Bruno Soares M, Alexander M, Dessai S (2018) Sectoral use of climate information in Europe: a synoptic overview. Clim Services 9:5-20

CARE (2016) Making sure users get the climate information they need for decision making: how to bridge the gap in user-based climate services? Presented at UK Department for International Development. CARE International, London

Cochrane L, Singh R (2017) The changing role of NGOs in supporting climate services. BRACED report, Overseas Development Institute: London. http:/www.braced.org/contentAsset/raw-data/d9979304-b9bc-46 bd-9bd0-74332efbe852/attachmentFile. Accessed 25 Mar 2019

Crawford A, Price-Kelly H, Terton A, Echeverría D (2016) Review of current and planned adaptation action in Burkina Faso. CARIAA Working Paper no. 17. International Development Research Centre, Ottawa, Canada and UK Aid. London: United Kingdom

Crawley F, Camilla A, Visman, E (2018) Interactions between local and scientific knowledge systems for weather and climate services. Building Resilience and Adaptation to Climate Extremes and Disasters (BRACED). London: UK. http://www.braced.org/contentAsset/raw-data/381de69d-73c8-41c7-87c1-a3a5 d8d13d87/attachmentFile. Accessed 25 Mar 2019

Diasso UJ (2016) Burkina Faso mission report. UNDP CIRDA http://undpcirda.blogspot.co.uk/2016/05/burkinafaso-mission-report.html. Accessed 25 Mar 2019

Dilling L, Lemos MC (2011) Creating usable science: Opportunities and constraints for climate knowledge use and their implications for science policy. Glob Environ Chang 21(2):680-689

Dinku T, Block P et al (2014a) Bridging critical gaps in climate services and applications in Africa. Earth Perspect 1:15

Dinku T, Hailemariam K, Maidment R, Tarnavsky E, Connor S (2014b) Combined use of satellite estimates and rain gauge observations to generate high-quality historical rainfall time series over Ethiopia. Int $\mathrm{J}$ Climatol 34(7):2489-2504

Echeverria D, Terton A (2016) Review of current and planned adaptation action in Ethiopia. CARIAA Working Paper no. 8. International Development Research Centre, Ottawa, Canada and UK Aid, London, United Kingdom

Eriksen SH, Nightingale AJ, Eakin H (2015) Reframing adaptation: the political nature of climate change adaptation. Glob Environ Chang 35:523-533

Georgeson L, Maslin M, Poessinouw M (2017) Global disparity in the supply of commercial weather and climate information services. Sci Adv 3(5):e1602632

GFCS (2016) Emerging priorities for climate services investment in Burkina Faso. Global Framework for Climate Services, Dakar

Giuliani G, Nativi S, Obregon A, Beniston M, Lehmann A (2017) Spatially enabling the Global Framework for Climate Services: reviewing geospatial solutions to efficiently share and integrate climate data \& information. Clim Services 8:44-58 
Golding N, Hewitt C, Zhang P, Bett P, Fang X, Hu H, Nobert S (2017) Improving user engagement and uptake of climate services in China. Clim Services 5:39-45

Grist N, Harvey B (2017) Framing innovations for climate resilience for farmers in the Sahel. BRACED resilience Intel paper 9. Overseas Development Institute, London

Guido Z, Rountree V, Greene C, Gerlak A, Trotman A (2016) Connecting Climate information producers and users: boundary organization, knowledge networks, and information brokers at Caribbean climate outlook forums. Weather Clim Soc 8(3):285-298

Guthiga P, Newsham A (2011) Meteorologists meeting rainmakers: indigenous knowledge and climate policy processes in Kenya. IDS Bull 42(3):104-109

Hammill A, Harvey B, Echeverría D (2013) Knowledge for action: an analysis of the use of online climate knowledge brokering platforms. Knowl Manag Dev J 9(10):72-92

Harrison M, Kanga A et al (2007) Use of seasonal forecasts and climate prediction in operational agriculture. CAgM Report No. 102, World Meteorological Organization, Geneva

Harvey B, Singh R (2017) Climate services for resilience: the changing roles of NGOs in Burkina Faso. BRACED report. Overseas Development Institute, London http://www.braced.org/contentAsset/rawdata/bb3dc391-5ebd-4d6e-899b-3836f69cf196/attachmentFile. Accessed 25 Mar 2019

Hewitt C, Mason S, Walland D (2012) The global framework for climate services. Nat Clim Chang 2(12):831

Huitema D, Turnhout E (2009) Working at the science-policy interface: a discursive analysis of boundary work at the Netherlands Environmental Assessment Agency. Environ Politics 18(4):576-594

Hulme M, Biot Y et al (1992) Seasonal rainfall forecasting for Africa part II—application and impact assessment. Int J Environ Stud 40(2-3):103-121

Ingram KT, Roncoli C, Kirshen PH (2002) Opportunities and constraints for farmers of West Africa to use seasonal precipitation forecasts with Burkina Faso as a case study. Agric Syst 74(3):331-349

Jad I (2007) NGOs: between buzzwords and social movements. Dev Pract 17(4-5):622-629

Jones L, Dougill A et al (2015) Ensuring climate information guides long-term development. Nat Clim Chang 5(9):812

Jones L, Harvey B, Godfrey-Wood R (2016) The changing role of NGOs in supporting climate services. BRACED Resilience Intel, 4. Overseas Development Institute, London

Jones L, Harvey B et al (2018) Designing the next generation of climate adaptation research for development. Reg Environ Chang 18(1):297-304

Kalanda-Joshua M, Ngongondo C, Chipeta L, Mpembeka F (2011) Integrating indigenous knowledge with conventional science: enhancing localised climate and weather forecasts in Nessa, Mulanje, Malawi. Phys Chem Earth A/B/C 36(14-15):996-1003

Korecha D, Sorteberg A (2013) Validation of operational seasonal rainfall forecast in Ethiopia. Water Resour Res 49:7681-7697

Krauss W, von Storch H (2012) Post-normal practices between regional climate services and local knowledge. Nat Cult 7(2):213-230

Lourenço TC, Swart R, Goosen H, Street R (2015) The rise of demand-driven climate services. Nat Clim Chang $6(1): 13$

Lúcio FDF, Grasso V (2016) The global framework for climate services (GFCS). Clim Services 2-3:52-53

Malo, S (2019) Local funding fears as Britain sunsets climate resilience programme. Thomson Reuters Foundation News. Available at: http://news.trust.org/item/20190222112633-frzj5/. Accessed 25 Mar 2019

Mason S, Chidzambwa S (2008) Verification of African RCOF forecasts. World Meteorological Organization RCOF Review, 09-02

Meadow AM, Ferguson DB et al (2015) Moving toward the deliberate coproduction of climate science knowledge. Weather Climate Soc 7(2):179-191

Naess LO, Newell P, Newsham A, Phillips J, Quan J, Tanner T (2015) Climate policy meets national development contexts: insights from Kenya and Mozambique. Glob Environ Chang 35:534-544

Niang I, Ruppel OC, Abdrabo MA, Essel A, Lennard C, Padgham J, Urquhart P (2014) Africa. In: V. R et al (eds) Climate change 2014: impacts, adaptation, and vulnerability. Part B: regional aspects. Contribution of Working Group II to the Fifth Assessment Report of the IPCC. Cambridge University Press, Cambridge, pp 1199-1265

Nyong A, Adesina F, Osman Elasha B (2007) The value of indigenous knowledge in climate change mitigation and adaptation strategies in the African Sahel. Mitig Adapt Strateg Glob Chang 12(5):787-797

Pauw WP (2014) Not a panacea: private-sector engagement in adaptation and adaptation finance in developing countries. Clim Pol 15(5):583-603

Plotz RD, Chambers LE, Fin CK (2017) The best of both worlds: a decision-making framework for combining traditional and contemporary forecast systems. J Appl Meteorol Climatol 56(8):2377-2392 
Powell A, Percy F et al (2017). NGO statement for the AMCOMET Africa Hydromet Forum. https://www.wmo. int/amcomet/sites/default/files/field/doc/events/ngo_statement_for_the_africa_hydromet_forum_final.pdf (Accessed 20 Mar 2018)

Reinecke S (2015) Knowledge brokerage designs and practices in four European climate services: a role model for biodiversity policies? Environ Sci Pol 54:513-521

Roncoli C, Jost C et al (2009) From accessing to assessing forecasts: an end-to-end study of participatory climate forecast dissemination in Burkina Faso (West Africa). Clim Chang 92(3-4):433

Silva Villanueva P, Gould C, Pichon F (2016) Routes to resilience: Insights from BRACED year 1. ITAD, Hove

Tall A, Hansen J et al (2014) Scaling up climate services for farmers: mission possible. Learning from good practice in Africa and South Asia. CCAFS report no. 13. CGIAR Research Program on Climate Change, Agriculture and Food Security (CCAFS), Copenhagen

Tarhule A, Lamb PJ (2003) Climate research and seasonal forecasting for West Africans: perceptions, dissemination, and use? Bull Am Meteorol Soc 84(12):1741-1759

UNDP (2016) A new vision for weather and climate information services in Africa. United Nations Development Programme, New York

Vaughan C, Dessai S (2014) Climate services for society: origins, institutional arrangements, and design elements for an evaluation framework. WIRES Clim Chang 5(5):587-603

Visman E, Audia C et al (2017) Developing decision-relevant climate information and supporting its appropriate application. Learning Paper \#6, for the Christian Aid-led BRACED consortia. King's College London, London

Webber S (2017) Circulating climate services: commercializing science for climate change adaptation in Pacific Islands. Geoforum 85:82-91

Webber S, Donner SD (2017) Climate service warnings: cautions about commercializing climate science for adaptation in the developing world. WIRES Clim Chang 8(1):1-8

Wilkinson E, Budimir M, Ahmed AK, Ouma G (2015) Climate information and services in BRACED countries. BRACED Resilience Intel 1. Overseas Development Institute, London

Windrum P, Schartinger D, Rubalcaba L, Gallouj F, Toivonen M (2016) The co-creation of multiagent social innovations. Eur J Innov Manag 19(2):150-166

Ziervogel G, Opere A (2010) Integrating meteorological and indigenous knowledge-based seasonal climate forecasts for the agricultural sector: lessons from participatory action research in sub-Saharan Africa. CCAA learning paper, 1. International Development Research Centre, Ottawa

Publisher's note Springer Nature remains neutral with regard to jurisdictional claims in published maps and institutional affiliations.

\section{Affiliations}

\section{Blane Harvey ${ }^{1,2} \cdot$ Lindsey Jones ${ }^{2,3} \cdot$ Logan Cochrane $^{4,5} \cdot$ Roop Singh $^{6}$}

1 McGill University, Montreal, QC H3A 0G4, Canada

2 Overseas Development Institute, London, UK

3 Grantham Institute on Climate Change and the Environment, London School of Economics, London, UK

4 Carleton University, Ottawa, ON K1S 5B6, Canada

5 Hawassa University, Awassa, Ethiopia

6 Red Cross Red Crescent Climate Centre, The Hague, Netherlands 